\title{
MethOd FOR EVALUATING ReSEARCH AND GUIDELINE EVIDENCE
}

Jeannine Liddle,

Centre for Clinical Policy and Practice

$\mathrm{T}$ he NSW Health Department has published a monograph entitled Method for Evaluating Research and Guideline Evidence (MERGE)1. The monograph sets out a standardised approach to the process of reviewing and incorporating scientific evidence into clinical practice guidelines. MERGE is intended to assist in the application of principles for the development of guidelines, as proposed by the National Health and Medical Research Council's Quality of Care and Health Outcomes Committee. These principles are:
- Clinical practice guidelines should be based on the best available evidence.
口 The method used to synthesise the evidence should be the strongest available.
口 Guidelines should contain a statement concerning the strength of evidence ${ }^{2}$.

MERGE was written with input from epidemiologists working in Australia, the Cochrane Collaboration and clinician members of the NSW Health Department's Expert Panel on Diabetes Guidelines Working Group. The monograph consists of a series of checklists for evaluating the quality of evidence both from individual studies and intervention guidelines. It includes examples related to the management of diabetes.

Copies of MERGE can be obtained from the Better Health Centre, 162 Blues Point Road, North Sydney, NSW 2060. Facsimile: (02) 9955 5196, telephone: (02) 99541193.

MERGE is also available on the NSW Health Department website: http://www.health.nsw.au/public health

1. Liddle J. Williamson M, Irwig L. Method for Evaluating Research and Guideline Evidence. NSW Health Department, Sydney, December 1996. 2. NHMRC Quality of Care and Health Outcomes Committee. Guidelines for the development and implementation of clinical practice guidelines. Australian Government Publishing Service, Canberra, October 1995.

\section{Hepatitis A outbreak}

\section{Continued from page 1}

(unadjusted matched odds ratio $7, \mathrm{p}<0.001$ ). In the great majority of instances where the source of the oysters was known, it was Wallis Lake. That day, a public warning was issued, linking the outbreak to consumption of Wallis Lake oysters. In collaboration with the oyster industry and other government departments, harvesting of these oysters was ceased and steps towards a voluntary recall of the product were begun.

As of March 9, 1997, we had received more than 370 notifications of hepatitis A cases with onset after January 21 (almost four times the number expected for this time of year). Over a similar period, excess cases were also recorded in Queensland, South Australia, Victoria and the Australian Capital Territory. One death - that of a man aged 77 years - has been attributed to the epidemic. The peak reported date of onset was February 3 (28 cases), and the peak reported date of oyster purchase among cases who ate oysters on a single occasion during their incubation period was January 4 . Hepatitis A virus was identified by polymerase chain reaction amplification (PCR) techniques in a batch of oysters taken from a Wallis Lake oyster lease on February 18.
Wallis Lake (one of the estuarine Great Lakes on the mid-north coast of NSW, in the Forster-Tuncurry area) is one of the largest oyster growing areas in Australia. During the Christmas and New Year period, the distribution of the Sydney Rock Oyster (the species grown in Wallis Lake) was extensive. An environmental audit of the Lake and environs is in progress. An inter-Departmental task force, chaired by the Chief Health Officer, is working on the definition of criteria to be fulfilled before the lake can be reopened for oyster harvesting.

A more complete report of the outbreak investigation will appear in a future issue of the NSW Public Health Bulletin.

1. Melnick JL. History and Epidemiology of Hepatitis A virus. JID 1995; 171(suppl 1):S2-8.

2. Benenson AS (Ed). Control of Communicable Diseases Manual (16th Edition). American Public Health Association.

3. Desenclos JA, Klontz KC, Wilder $\mathrm{MH}$ et al. A multistate outbreak of hepatitis A caused by the consumption of raw oysters. Am J Public Health 1991; 81:1268-1272. 